\title{
Developing medical device technologies from users' \\ perspectives: A theoretical framework for involving users in the development process
}

\author{
Syed Ghulam Sarwar Shah ${ }^{1,}$, Ian Robinson², Sarmad AlShawi ${ }^{3}$
}

\section{Brunel University}

${ }^{1}$ Research Fellow, Multidisciplinary Assessment of Technology Cente for Healthcare (MATCH), Brunel University, Uxbridge, Middlesex, UB8 3PH, UK

${ }^{2}$ Professor Emeritus, Centre for the Study of Health and 41 lness, School of Social Sciences \& Multidisciplinary Assessment of Technology Centase for Healthcare (MATCH), Brunel University, Uxbridge, Middlesex, UB8 3PH, UK

3 Lecturer, Brunel Business School \& Multidisčiplinary Assessment of Technology Centre for Healthcare, Brunel University, Uxbridge Uiddlesex UB8 3PH, UK

${ }^{*}$ Corresponding author

Tel 0044 (0)1895 265 463; Fax 0044 (0)1895 237573

Email: Sarwar.Shah@brunel.ac.uk

Note This is pre-published version of manuscript published in the International Journal of Technology Assessment in Health Care / Volume 25 / Issue 04 / October 2009, pp 514-521. DOI: http://dx.doi.org/10.1017/S0266462309990328 


\section{ABSTRACT}

Objectives: To suggest an acceptable and generic theoretical framework for involving various types of users in the medical device technology (MDT) development process (MDTDP).

Methods: The authors propose a theoretical framework suggesting different routes, methods and stages through which various types of medical device users can be involved in the MDTDP.

Results: The suggested framework comprises two streams of users' injolvement in MDT development i.e. what might be called the end users' streapeand the professional users' stream for involving these two groups respectively inthe process of developing both simple and more complex and innovative medicaldevices from conceptualisation through to the market deployment. This framesork implies various methods that can be used for users' involvement at differentistages of the MDT lifecycle. To illustrate the application of the framework, a numberer of MDT development scenarios and device exemplars are presented.

Conclusions: Development of medical devices from users' perspectives requires not only the involvementifof healthcare professionals but also that of the ultimate end users i.e. patients, peple with disabilities and/or special needs, and their caregivers. The evidenceshows that such end users quickly discard devices that do not fulfil their sic personal expectations, even though both manufacturers and healthcare professionals may consider those end users' requirements met. Developers and manufacturers need to recognise this potent potential discrepancy between the parties involved, and involve end users and professional healthcare staff directly in the MDTDP. The framework, the authors contend, is a step forward in helping medical device manufacturers plan and make decisions about users' involvement at different stages of the MDTDP. 
Keywords: User involvement, Device development process, Medical device technology assessment, User perspective, Conceptual framework.

\section{INTRODUCTION}

Medical device technologies (MDTs) include medical devices and assistive devices (35), which have been defined elsewhere $(14 ; 38)$. There are a range of, often competifig perspectives, concerning MDT such as regulators' perspectives, manufacers' perspectives and users' perspectives. All these perspectives are important to assess and synthesize, but users' perspectives is particularly important fot the success of a device. Users of MDTs are not homogeneous as they are often inaphicitly considered to be, but are constituted by different types and groups of pexple such as healthcare professionals, carers and end users e.g. patients, people withqodisabilities and/or special needs and elderly people, with different roles and yoterests (35). Involvement of the users is essential because they expect that medical device that is supplied to them, or that they buy and use, fulfills their personal needs and requirements, which may indeed vary from one user to anotherecterally in the case of end users. The most effective way of developing MDTs som users' perspective therefore can be done by involving the healthcare professionals as well as the end users. For devices that are intended for the use byend users, views of and acceptance by end users is crucial to the device's role and longevity, no matter how well the device is manufactured, and how strongly it is recommended by healthcare professionals.

There is published evidence that end users' involvement in the MDT development process (MDTDP) is associated with several substantial advantages for manufacturers. For example, the generation of ideas for new products and product 
innovation; access to users' actual requirements and expectations; a reduction in development costs; an improvement in device design, usability and safety; and the identification of potential problems at an early stage of the device development cycle, thus limiting costly device modifications and a reduction in device recalls $(25 ; 34)$. Manufacturers therefore need to engage with the range of users of MDTs and involve them, as early as possible, in the development process (12).

Up to now evidence on users' involvement in the MDTDP is clearly fogusised on the views of healthcare professionals, particularly clinicians and nursegathile other types of MDT users, especially end users, such as patients, people divith disabilities and/or special needs, elderly people and carers, particularly be involved in the process $(4 ; 11, p .173 ; 25 ; 33)$. The appantently minimal involvement of the end users (who we also call as non-healthcakeprofessional users), can be for various reasons including their personal characteristics and a need for supporting, preparing and training them to enablettheir involvement in the MDTDP (34).

According to Andre et al (xis), user involvement depends and/or is facilitated by the availability of an appro framework. In relation to MDT, a number of frameworks have beenused. For example, the technology transfer model (36); the economic evaluation in health technology assessment (32); a framework for the development and evaluation of randomised controlled trials (8;26); a model of user engagement in medical device development (15), and the integration of a Bayesian 4famework in the medical device development cycle (37). However, no universal and formal framework for the involvement of users, especially end users, in the process of MDT manufacturing from concept development through to the market deployment has been reported in the literature $(4 ; 25 ; 33)$. In the absence of an acceptable and proper framework, a meaningful users' involvement cannot occur systematically across the 
medical device sector but it will take place haphazardly. This has had, and is likely to have, negative repercussions for both manufacturers and users of MDTs, for example the continuous abandonment of the devices by their users (3). There is therefore a need for an acceptable and generic framework for involving various types of users in the MDTDP. The authors therefore propose such a framework in this paper. However, before presenting our conceptual framework, we briefly describe some key concertis, i.e. stages of MDT development cycle, methods of involving users and types of MNT users, on which the framework is based.

\section{Stages in MDT Lifecycle Relevant for Involving Usens}

The lifecycle of a medical device can be divided into several stages, over which there is some debate. Cooper and Kleinschmidt (9) describat 13 stages in the lifecycle of a medical device, which were modified to 12 stagés by Rochford and Rudelius (31). Elsewhere, seven stages of the medical device lifecycle have been mentioned (38). Shah and Robinson (33) reviewed the derent stages of medical device lifecycle reported in a wide range of analyses and determined that the various stages of the medical device lifecycle can be placed idoto five key phases:

\section{Stages'of the Medical Device Lifecycle}

- Concept stage (idea generation and concept development)

- Design stage (device (re-)design and prototype development)

- Testing and trials stage (prototype testing in-house and trials in the real field)

- Production stage (device production based on business and commercial rational)

- Deployment stage (product launch and use in the market and post-deployment user feedback) 
Literature shows that users can be involved at four stages, i.e. concept, design, testing and trials, and deployment stages, of the above-mentioned five stages (33). We therefore suggest these four stages can best be used to develop our theoretical framework for involving users in MDTDP (Figure 1).

\section{Methods for Involving Users}

Recent published work suggests several methods that have been user for involving

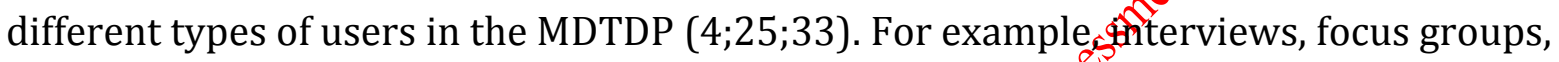
usability tests, customer feedback, cognitive walkthrough, and producers seminars and field observation methods used for involving the end users, such as patients, people with disabilitiesand/or special needs and lay carers, and the professional users, e.g., physicians, general practitioners, surgeons, nurses, cardiologists, radiologists, MRI prossionals and physicists) in the development process of different types of सुDT. For instance, an inhaler (1), assistive devices such as robotic aids, wheel chaîrs, wheeled mobility devices $(3 ; 6 ; 7 ; 20 ; 28)$, ventilators (13), teleradiology systên (16), neuromagnetometer (17;27), intraventicular blood pump (18), telemedicine system (19), patient monitoring system (22), patient-controlled analgesia pump (23), and infusion pumps (12;29;39).

In our theoretical framework, we will be suggesting that many of the methods mentioned above can be successfully and directly deployed in relation to the involvement of the professional users and the end users at four different stages of the MDT lifecycle (Figure 1). 


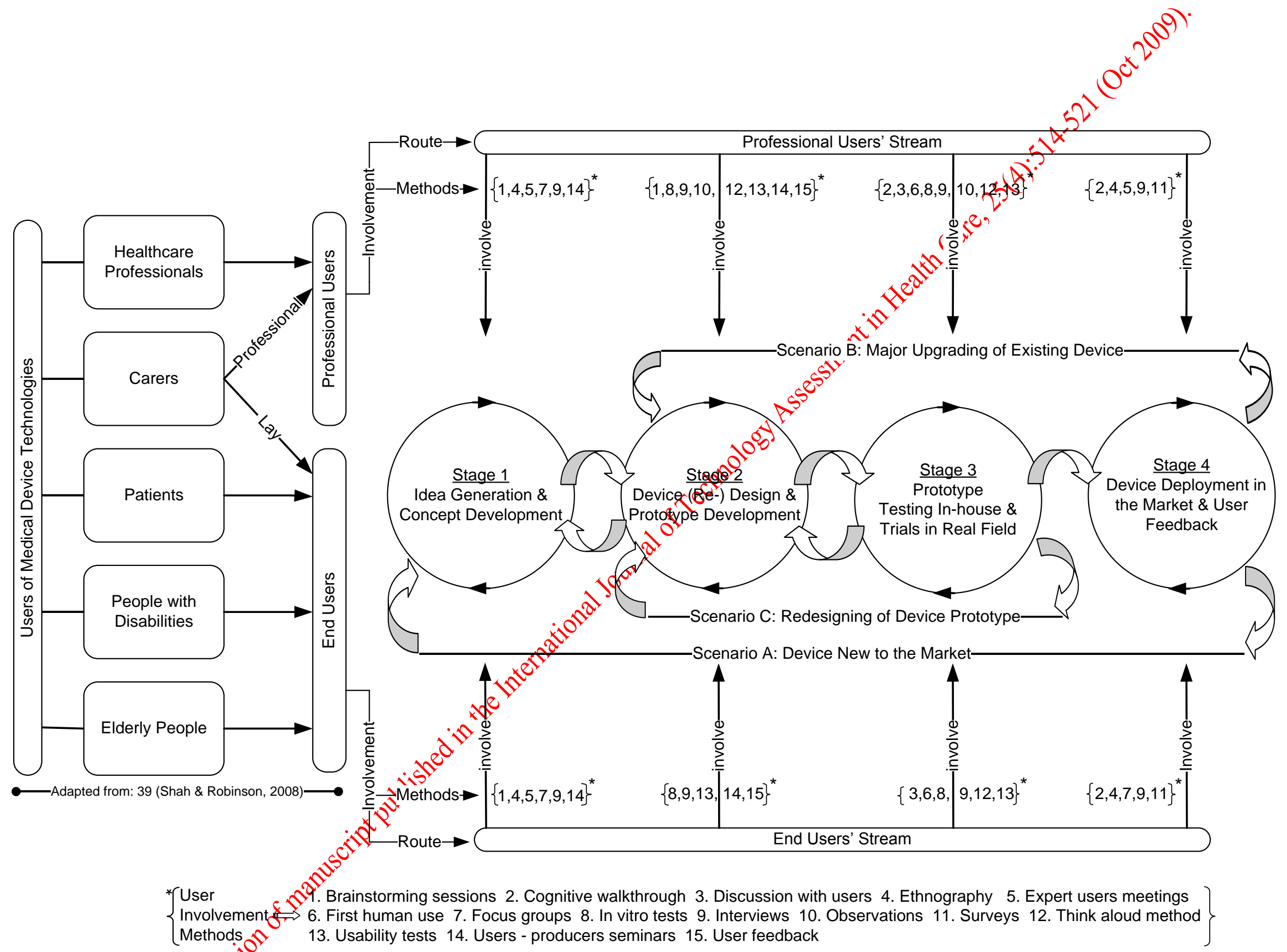

Figure 1. Theoreticaldramework for involving users in the medical device technology development process: streams, methods and stages 1. Theoreticald dramework for involving users in the medical device technology development process: streams, methods and stages 


\section{Users of Medical Device Technologies}

Primary users of medical devices can be divided, based on their professional and personal traits, into different groups, such as healthcare professionals, patients, people with disabilities and/or special needs, elderly people and carers i.e. professional and lay carers (35). In addition, Shah and Robinson (35) are of the opinion that professionak people use the devices for the benefit of patients, people with disabilities and/orspecial needs and elderly people - whom they describe collectively as 'end users'

In order to clarify further the term 'user' here, which often inspractice has led to confusion in studies as to whom exactly is referred to by the texhm, we think medical device users can be classified into two major categories i.e. end users (non-professional users) and professional users. The former category inay include patients, people with disabilities and/or special needs, elderly peopte and lay carers, essentially those non health care professionals directly using devices, whilst the professional users may include a wide range of healthcare classification is based on a factual assumption that end users generally have no or less formal qualifications and training while the professional users are fully and properly qualified and skillagd to use specific MDTs. In addition, they differ from each other in several otherchays. In describing our framework, we will therefore use only two terms i.e. 'end Uै'sers' and 'professional users' for those who employ MDTs (Figure 1).

\section{CONCEPTUAL FRAMEWORK FOR USERS' INVOLVEMENT}

It is noteworthy that the MDTDP is an iterative process starting from idea generation and concept development through to device design and prototype development and testing, and device deployment in the market (5). We believe that the involvement of 
users can be through an iterative process that can take place at different points in the MDT lifecycle (Figure 1). We also believe that in developing a MDT there can be three possibilities as under.

\section{MDT Development Scenarios}

Scenario A: Device New to the Market. In the case of development of a device new to the market, a lengthy and detailed iteration from the stage of concept development through to the stage of deployment / launching the device in the market will be required (Figure 2a). This type of device can be developed using either an existing technology or a ne

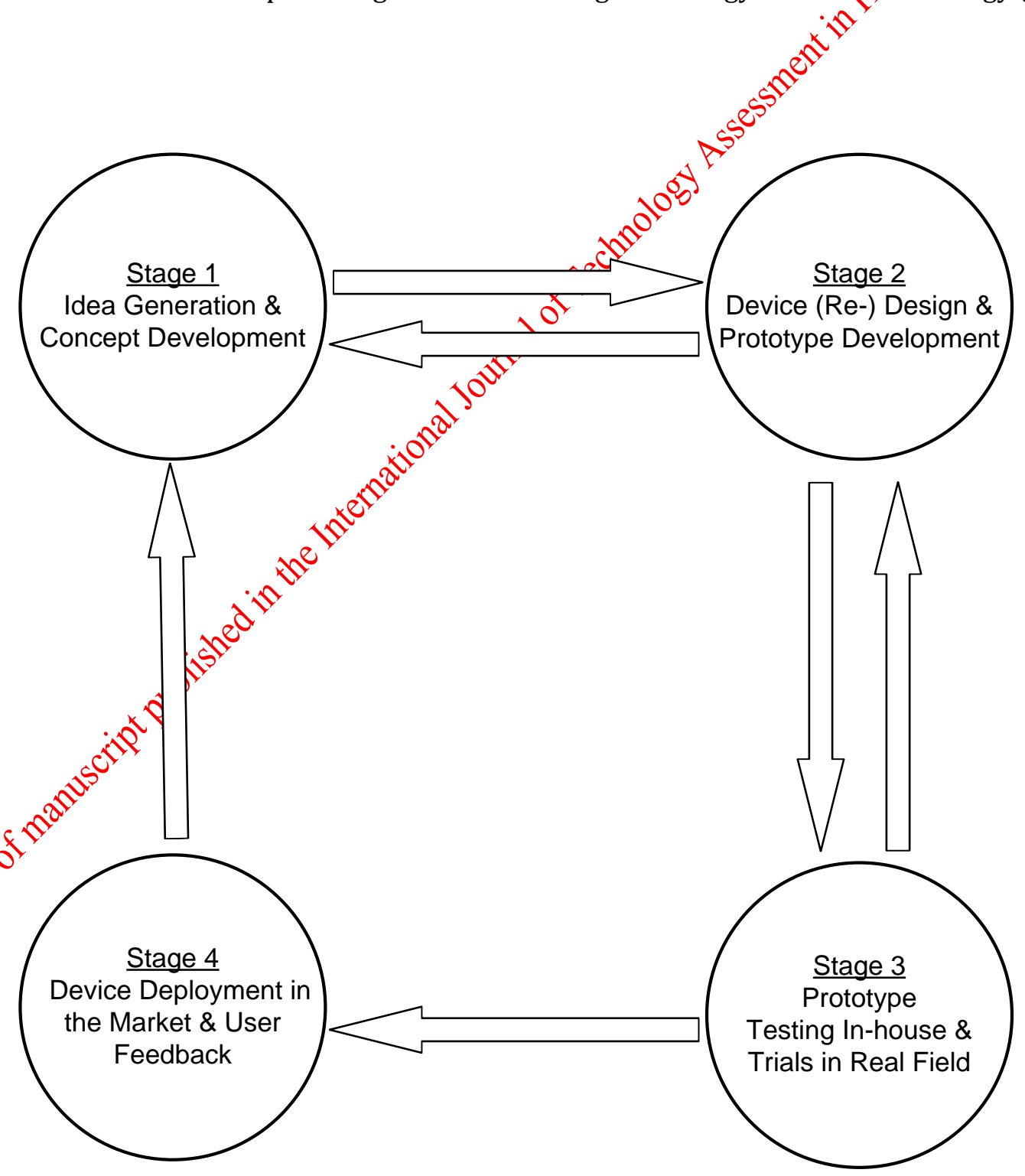

Figure 2a. MDT development scenario A: Device new to the market 
Scenario B: Major Upgrade of an Existing Device. A major upgrade of an existing

device will involve an iterative process between the design and prototype development stage, prototype testing and trials stage and deployment stage (Figure $2 \mathrm{~b}$ ).

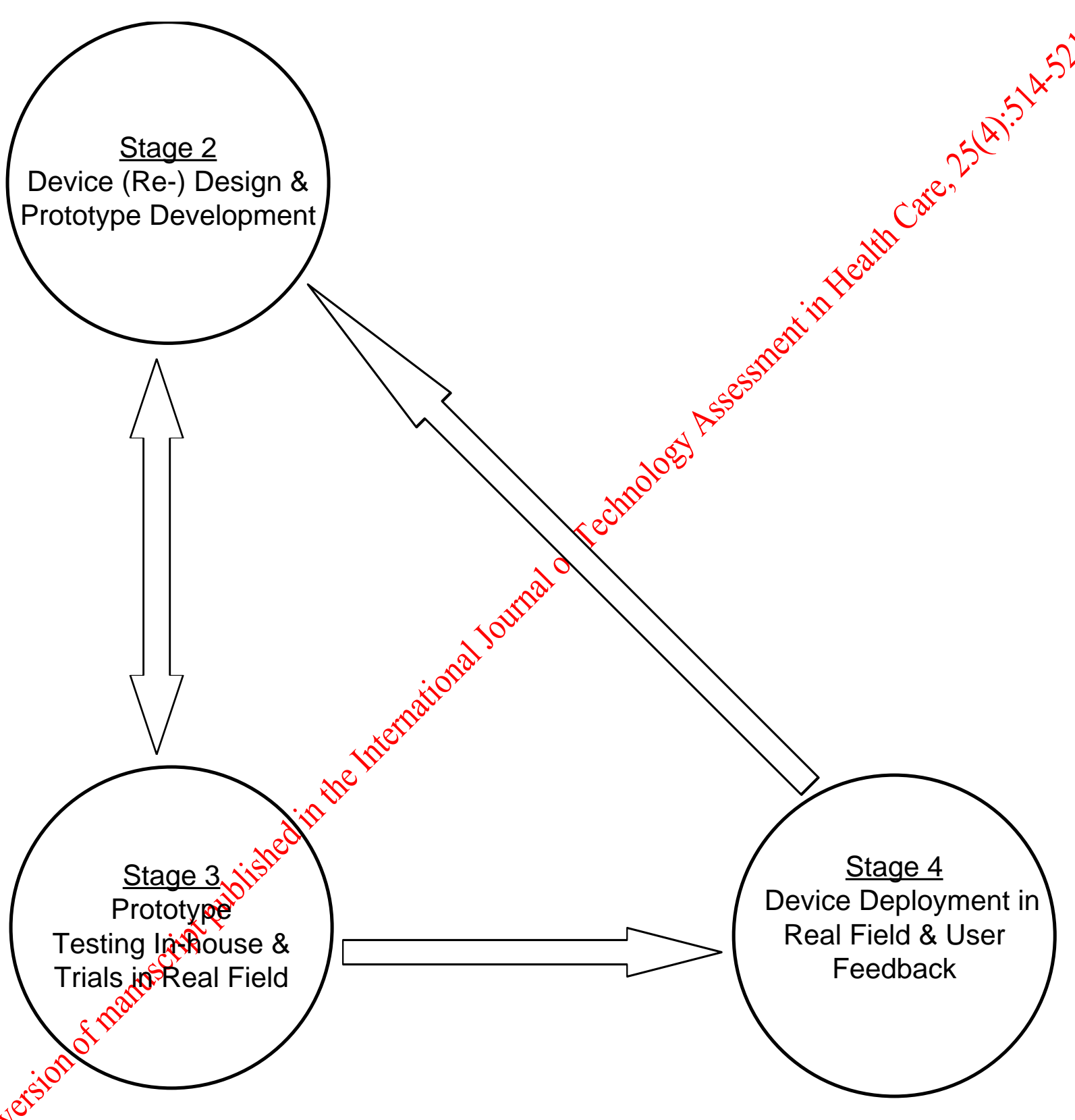

Figure 2b. MDT development scenario B: Major upgrading of existing device 
Scenario C: Redesigning of a Device Prototype. The redesigning of a device prototype

will involve an iterative process mainly between the design and prototype development stage and prototype testing and trials stage (Figure 2c). For prototype redesigning, users' ideas can be helpful that can be solicited through their involvement via the idea generation and concept development stage.

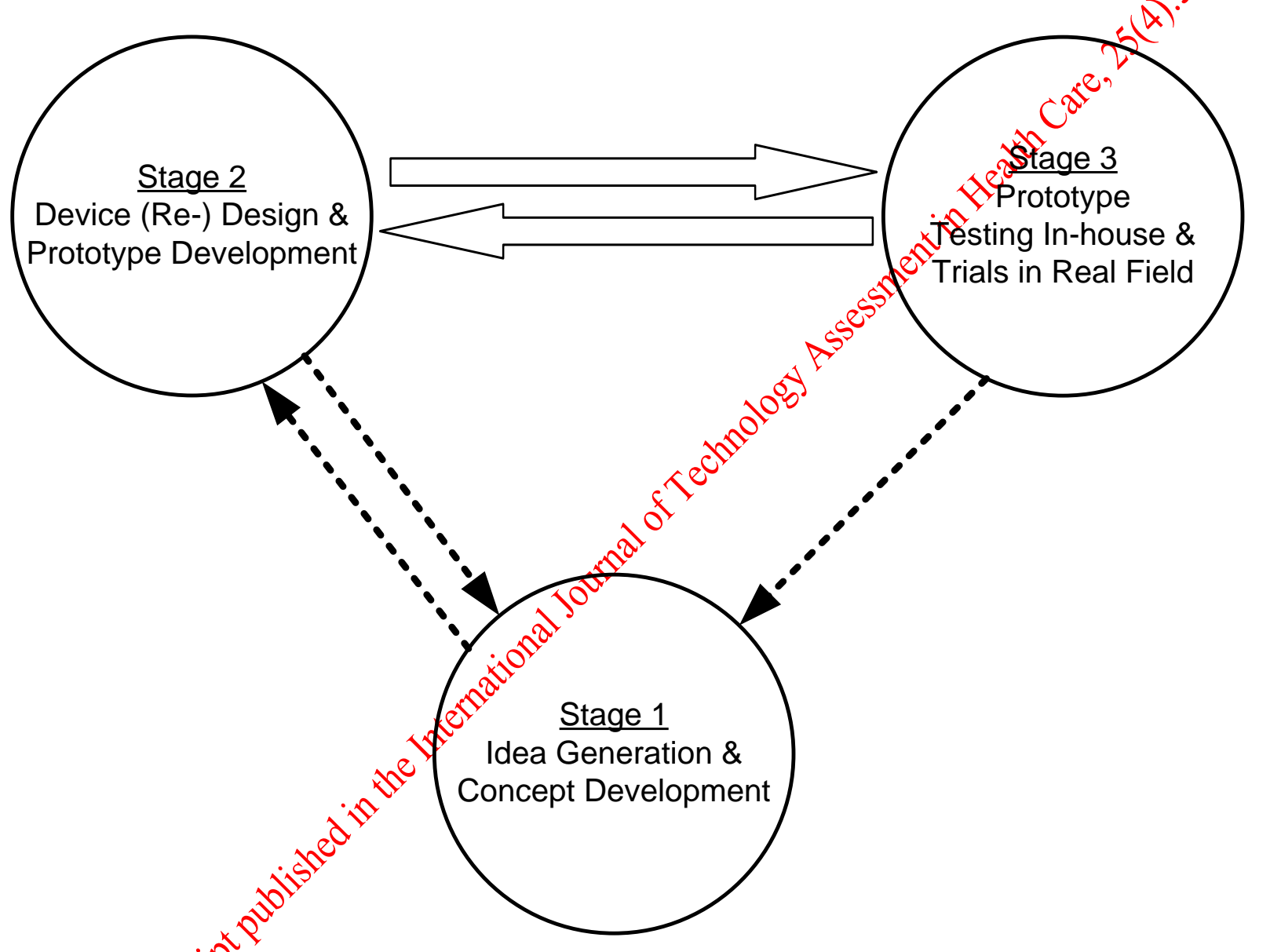

Bearing in mind these possible scenarios and the iterative process of developing MDTs, we propose a conceptual framework (Figure 1), which suggests two routes by which involvement of particular types of users may be exercised and various methods can be applied for involving users in various ways at four different stages of the device lifecycle, as follows. 


\section{User Involvement Streams}

In this framework (Figure 1), we suggest two routes i.e. end users' stream and a professional users' stream for involving users in the MDTDP. Each of the streams covers four stages starting from the idea generation and concept development, device design and prototype development, prototype testing and trialling through to the market deployment of the device. These four stages of users' involvement are proposed for the development of a device that is new to thé market (Scenario A) (Figure 2a). However, as we have noted, major upgrading of an existing device (Scenario B) will generally involve three stages i.e. designing, testing and trylling and deploying of the device in the market (Figure 2b), on the other hand redesighing of a prototype (Scenario C) will require iterative user involvement primarily betweentwo stages i.e. the design and prototype development stage and the testing and trials stage however, soliciting users' opinions via the concept (idea generation) stage can be hedoful (Figure 2c). The operation of the streams is described below.

\section{End Users' Stream}

We suggest that the 'end users' (EU) steam (Figure 1) is deployed for the involvement of end users i.e. patients, persons with distabilities and/or special needs and elderly people, in addition to lay carers. In general, thisstream would be used by MDT developers for MDTs that will be used only by the enditsers themselves, and/or their carers as proxies for them, generally outside clinical:settings and usually at their homes. We believe that devices used by the end users can be relatively simple and less complex as well as more complex and/or innovative. We therefore put forward two device exemplars for the application of this stream.

Exemplar 1. A medical device that will be used by the end user(s) and the device will not be very complex. For example, an inhaler device.

In the case of this type of MDT, the developers can use the EU stream, and involve end users in the iterative process between various stages of the device development cycle as 
mentioned in and depending on the MDT development scenarios described above. In developing this type of devices, manufacturers can involve professional users, particularly healthcare professionals, such as clinicians, through professional users' (PU) stream for obtaining their opinions and suggestions regarding the device.

Exemplar 2. A medical device that will be used by the end user(s) and the device wid b be more complex and/or innovative. For example, assistive devices such as a robotic aid.

Developing this type of MDT, there can also be three scenarios mentionedCearlier. In the case of developing this type of device new to the market, it is possible that cancept come from the end user(s), the professional user(s) or the manufacturer. If the concept was developed by the end user(s) then they should be involved iteratiofely as described in the MDT development scenario A (Figure 2a) and using the EU streame Figure 1). However, if the concept was developed by the professional user(s) or the maneffacturer, then a model may be more appropriate as that in scenario 4, described unders the PU stream.

In the case of major upgrade of this type of an existing device or redesigning of a prototype, end users can be involved described in the MDT development scenario B (Figure 2b) or scenario C (Figure 2c) respectively and through the EU stream (Figure 1). In all the three cases, manufacturers canjinvolve healthcare professionals particularly clinicians, through the PU stream (Figure 13 dit later stages i.e. testing and trials stage and deployment stage for obtaining their opinion and suggestions regarding the device.

\section{Profegsional Users' Stream}

suggest the professional users' (PU) stream for the involvement of professional users of MDTs (Figure 1). We propose that this stream should be used by MDT developers for creating medical devices that will be used only by the professional users i.e. healthcare professionals and/or professional carers for treating and/or caring for an end user or inserting/implanting the device in to the body of an end user by a healthcare professional. 
In this stream, professional users can be involved in iteratively between various stages of the device lifecycle depending on and as mentioned in the MDT development scenarios A, B and $\mathrm{C}$ described above. In addition, there will be a need to involve the end users, at the testing and trials stage and the deployment stage, to check the device performance. To make the application of the PU stream more plausible, we put forward two device exemplars.

Exemplar 3. A medical device will be used only by healthcare professional(s) for the treatment / diagnosis and/or care of the end user(s). For example, a neuromagentometer.

To develop this type of device, there can be three scenarios i.e. A, B and C as mentioned earlier. For developing this type of device new to market (Scenario A), the can be two possibilities. First, if professional user(s) such as surgeon(s) devestoped the device concept, then we suggest that s/he/they should be involved from the concept development stage, through to device design and prototype development, testing anderials and the deployment stages of the device (Figure $1 \& 2 \mathrm{a}$ ). Second, if the manufacturer developed the concept, then the professional users may not be involved at the concept development stage but at the latter stages. We however suggest that they should be potential limitations. For develgying MDTs as mentioned in Scenario B or Scenario C, manufacturer can involvejôfossional users at the stages and in the manner described in the respective scenarios need for end ugers' involvement at the testing and trials and the deployment stages to evaluate the device 20 erformance (Figure 1).

Exemplar 4. A device will be used by the end user(s) but a healthcare professional will insert/place it in to the body of the end user. The device is more complex and/or innovative. For example, an implantable medical device.

There can be three scenarios i.e. A, B and C, as mentioned earlier, to develop this type of device. In scenario A, if the concept was developed by the healthcare professional(s) then 
s/he/they can be involved at all four stages described in MDT development scenario A (Figures $1 \& 2 a)$. However, if the concept for developing this type of device came from the manufacturer, then the manufacturer may not involve healthcare professionals at the concept stage but at the device design and prototype development stage through to the testing and trials and deployment stages (Figures $1 \& 2 \mathrm{a}$ ). We however suggest that the manufacture involves healthcare professional at the concept stage to discuss the device concept to thrush out anys potential limitations. In the case of developing MDT as mentioned in scenarios B and G, manufacturers should involve the professional users as described in the respectivescenario (Figures $2 b$ \& c). Irrespective of the scenarios, there will however be a nee involve the end users at the testing and trials stage, and deployment stage to assess and performance.

\section{User Involvement Methods}

We suggest various methods (Figure 1) for involviog both the end users and the professional users, using the EU stream and the PU strean tespectively, in the MDTDP. The most common methods that we suggest for both typescof the users and the streams include interviews, focus groups, brainstorming sessions ansers-producers seminars at the concept stage; interviews, usability tests and users' feed back at the design stage; usability tests, interviews and discussion at testing and trials stage; ethnography, interviews and surveys for (post-) deployment stage of the device (Figugie i).

\section{DISCUSSION}

Praetice has been very varied in involving users in the MDTDP and sometimes user involvement, particularly end user involvement, is very modest. Low or limited user involvement could be due to a number of factors such as a lack of funds and time available to manufacturers who are operating in a very competitive market (34). It may also occur through the personal limitations of users (through cognitive, physical, or informational problems) to meaningfully participate in the MDTDP (34). Despite above-mentioned constraints, there is 
often a willingness among manufacturers to use feedback from users' in the development of MDTs. Nevertheless, there is then the poverty of effective frameworks to incorporate users' feedback in the MDTDP. It is the need for such a framework that we have addressed in this paper.

We have proposed a generic theoretical framework for directly involving both the end users (non-professional users) and the professional users in the MDTDP (Figure 1). We recognise that medical devices differ from each other depending on the nature and complexity of the technology involved, type of the intended user, the environment and context of the use and the type of medical condition for which the device(s) is used. The nature of medical devices and the type of the intended user are however the most critical issue intinvolving users in the MDTDP. In this framework, we have therefore suggested two roukes i.e. EU stream and PU stream (Figure 1) through which needs of the intended usersean be incorporated in the MDTDP.

In our framework, we have proposed thatif the medical device being developed is a simple device that will be used by the endusers then the EU stream will be the first choice to develop such device. This is because end users know their needs better than any body else. In addition, we assume, end users, the their lay carers, might already have used a similar device at some point in time; therefore, they may have experience and knowledge of the limitations of using such a device. existing devices is well as developing a new device that can be used for a similar purpose. It is also possiafe that healthcare professionals, and professional carers, can convey some of the needs and requirements of the end users, which they have come to know often through early Contact with some of the end users. Manufacturers can therefore also involve professional users through the PU stream to get their perspectives about the device. An example is the development of an inhaler by Anderson et al (1), who involved both the end users i.e. asthma patients and their lay carers, and professional users i.e. physicians, general practitioners and asthma nurses from the concept and design development stages through to the testing and trials 
stages and their perspectives were obtained by various methods, such as interviews, focus groups, usability tests and user feedback.

Our framework suggests that if the MDT being developed is both complex and/or innovative, which is to be used by either the end user or the professional user, and a healthcare professional, a professional carer, and/or a manufacturer suggested the concept, then the PU stream should be the first choice to develop such device. Nevertheless, the involvement of end users will be required at the later stages in particular during testing and trialing stage and at the stage of device deployment in the market to assess and evaluate the device performance. For example, involvement of both healthcare professionals and end users in the development process of a neuromagnetometer - a complex device that is used by heathcare professionals for the analysis of the human cortex (brain) activity in patients with fertain medical conditions, such as epilepsy and brain tumours $(17 ; 27)$. There is a funtber example of such a deployment in relation to a complex and innovative device developedef rough users' involvement, which is the Gynecare TVT Secure System device for female stress urinary incontinence. This device was primarily developed by involving mainly professionals staff such as uro-gynaecologists and urologists, a primary route similar to users (female patients with stress urinary incontinence) were used at the testing and trialing stage and deployment stage, a secondary route similar to that proposed in the EU stream mentioned in our frantework (Personal email communication from Peter A. Meier, Principal Scientist, Researeh \& Development, ETHICON GmbH, Germany). It is important to bear in mind that end users may not possess sufficient technical knowledge and understanding about such<smiles>[SiH3]</smiles>
complex products to be able to fully give incisive assessments about them. Manufacturers therefore should not expect end users to solve major technical problems, therefore their involvement should be mainly for the purpose of identifying and clarifying their requirements and the vital features of the devices for them (21). Nevertheless, for innovative devices such as in relation to emerging medical technologies, end users can still be extensively involved at the testing stage of the device prototype (6). 
We do not prescribe specific method(s) for involving the users at any point in the MDTDP because we believe that the selection of those particular method(s) depends upon the resources, both money and time, and expertise available to the MDT developer. Developers should therefore decide themselves whether to use any particular method, taking into account costs and resources available, together with the type of data required and the quality of information obtainable through the method. There is no doubt that the involvement of users developing MDT is a protracted process; nevertheless, its impact on the device development is very great (6). "The manufacturers therefore need to build-in time and resource for such activities into the development plan and ensure end-user as well as professional-user value is captured in the product's value proposition" (Personal email communiegtion by Michael Borroff, Director of Strategic Health Outcomes, DePuy Internationfiri).

Limitations. The authors recognise limitations of thissframework such as the need for its validation, which will be undertaken in collaboratiog with our industrial partners, and the generality in its description. The latter is howeved done purposely to provide a generic framework and for ensuring involvement of different types of MDT users and to present it as an easily understood approach for manaers in the medical device manufacturing industry.

\section{POLICY IMPLICATIONS}

According to Marshall al (24), a 'designing for all' approach is required in product development to geet the needs of users particularly the needs of specific groups of end users.<smiles>[C]1CCCC1</smiles>

The PU streat is the most widely used route of users' involvement by the majority of device manufacturers. This practice has led medical research to be biased in favour of professional jesers, essentially only doctors / clinicians (30). We therefore would like to draw attention to a few important issues in this regard. Firstly, manufacturers must involve potential users, be they patients, healthcare professionals or carers who are actually going to use the device. Secondly, members of R\&D staff within manufacturing companies must not be assumed to predict accurately actual users' needs. Hence, it is unwise they should be involved as a total proxy on 
behalf of the real users of the device. Nevertheless, there are exceptions, for example if a particular member of R\&D who has ever used a device in his/her capacity either as a healthcare professional, caregiver or patient then he/she might be suitable to be involved in the development of such device and represent users' needs. Our framework (Figure 1) therefore ensures the involvement of different types of the medical device users to meet their specific and often hitherto unmet needs and requirements. Development of this conceptual work will support MDT manufacturers, particularly small and medium manufacturers (SMMs), wh́ may have limited expertise with regard to engagement with users, especially end users, in developing decision-making protocols regarding users' involvement in the

\section{CONCLUSION}

The development and evaluation of medical devices from usgess" perspectives requires not only the involvement of healthcare professionals but also thifo the ultimate end users i.e. patients, people with disabilities and/or special needs, and foir lay caregivers. This is because the needs of various types of the users vary widely frone other. The evidence shows that such end users quickly discard devices that do notfulfil their personal expectations, even though both manufacturers and healthcare pressionals may consider those end users' requirements met. MDT developers and manufacturers need to recognise this potent potential discrepancy between the parties inkolved, and involve end users as well as professional healthcare staff directly in the MRTYP. Nevertheless, the engagement of some types of medical device users, particularly end users may not always be possible for various reasons such as a lack of formally define (user involvement process, hence more formal approaches and a generic framework for jovolving end users needs to be developed and refined. The availability of a user involvement framework such as that proposed in this paper will help medical device manufacturers, particularly SMMs, in planning and developing strategies for involving end users and professional users in the MDTDP. 
Acknowledgments: This work was supported by the MATCH (Multidisciplinary Assessment of

Technology Centre for Healthcare), which is sponsored by the Engineering and Physical

Sciences Research Council, UK (Grant Nos. GR/S29874/01 and EP/G012393/1), although the

views expressed are entirely theirs. This is an extended version of the research work that was

orally presented at IVth Annual Meeting of Health Technology Assessment International held in

Barcelona, Spain in June 2007.

\section{REFERENCES}

1. Anderson GJM. Shaping the future: using voice of the customer methology to develop inhaler design. In: Dalby RN, Byron PR, Peart J, Farr SJ, eds., Procéetings of Respiratory Drug Delivery VIII Conference. Tucson, AZ. Serentec Press. Maye-16,2002;1:179-188.

2. Andre TS, Hartson HR, Belz SM, Mccreary FA. The user actiofframework: a reliable foundation for usability engineering support tools. Int J Hots Comput Stud. 2001;54:107136.

3. Batavia AI, Hammer GS. Toward the development of evaluation of assistive devices. J Rehabil Res Dey 990;27:425-436.

4. Bridgelal Ram M, Campling N, Grocott P, Weix fy methodology for a structured survey of the healthcare literature related to medifaldevice users. Evaluation. 2008;14:49-73.

5. Bridgelal Ram M, Grocott PR, Weir HCM. dssues and challenges of involving users in medical device development. Health Expect. 2008;11:63-71.

6. Buhler C. Approach to the analysis of user requirements in assistive technology. Int J Ind Ergon. 1996;17:187-192.

7. Buhler C, Hoelper R, Hoyer H. Autonomous robot technology for advanced wheelchair and robotic aids) for people with disabilities. Robot Auton Syst. 1995;14:213222.

8. Campbell M, Fitzpatrich R, Haines A, et al. Framework for design and evaluation of complex interventijo to improve health. BMJ. 2000;321:694-696.

9. Cooper RG, Kletuschmidt EJ. An investigation into the new product process: Steps, deficiencies id impact. J Prod Innov Manage. 1986;3:71-85.

10. Dixon D, Bewn A, Meenam BJ, Eatock J. Experiences of new product development in the medical \&evice industry. Med Device Technol. 2006;17:20-22.

11. Ekelowan KB, editor. New Medical Devices: Invention, Development, and Use. Washington, D. O.? National Academy Press; 1988.

12. Garmer K, Liljegren E, Osvalder A-L, Dahlman S. Application of usability testing to the development of medical equipment. Usability testing of a frequently used infusion pump and a new user interface for an infusion pump developed with a human factors approach. Int J Ind Ergon. 2002;29:145-159.

13. Garmer K, Ylven J, MariAnne Karlsson IC. User participation in requirements elicitation comparing focus group interviews and usability tests for eliciting usability requirements for medical equipment: A case study. Int J Ind Ergon. 2004;33:85-98.

14. Government of USA. Assistive Technology Act of 1998. Public Law 105-394- Nov 13, 1998, Vol 112 STAT. 1998.

15. Grocott $\mathrm{P}$, Weir H, Bridgelal Ram M. A model of user engagement in medical device development. Int J Health Care Qual Assur. 2007;20:484 - 493.

16. Handels $\mathrm{H}$, Rinast $\mathrm{E}, \mathrm{Busch} \mathrm{C}$, et al. Image transfer and computer-supported cooperative diagnosis. J Telemed Telecare. 1997;3:103-107. 
17. Hasu M. Constructing clinical use: An activity-theoretical perspective to implementing new technology. Technol Anal Strateg Manage. 2000;12:369-382.

18. Hummel M, van Rossum W, Omta O, et al. Types and timing of inter-organizational communication in new product development. Creativ Innovat Manag. 2001;10:225-233.

19. Kaufman DR, Patel VL, Hilliman C, et al. Usability in the real world: assessing medical information technologies in patients' homes. J Biomed Inform. 2003;36:45-60.

20. Kittel A, Marco AD, Stewart H. Factors influencing the decision to abandon manual wheelchairs for three individuals with a spinal cord injury. Disabil Rehabil. 2002;24:106114.

21. Lichter H, Schneider-Hufschmidt M, Zullighoven H. Prototyping in industrial software projects-bridging the gap between theory and practice. IEEE Trans Softw Eng. 1994;20:825-832.

22. Liljegren E, Osvalder A-L. Cognitive engineering methods as usability evaluation tónols for medical equipment. Int J Ind Ergon. 2004;34:49-62.

23. Lin L, Isla R, Doniz K, et al. Applying human factors to the design of medicalequipment: Patient-controlled analgesia.J Clin Monitor Comp. 1998;14:253-263.

24. Marshall R, Case K, Oliver R, et al. A task based 'design for all' suppotool. Robot Comput Integr Manuf. 2002;18:297-303.

25. Martin JL, Murphy E, Crowe JA, Norris BJ. Capturing user requirements in medical device development: The role of ergonomics. Physiol Meas. 2006;2 Z 2 49-R62.

26. Medical Research Council. A Framework for Development ofid Evaluation of RCTs for Complex Interventions to Improve Health. London: Medical Research Council Health Services and Public Health Research Board; 20001 April 2000.

27. Miettinen R, Hasu M. Articulating user needs in co Maborative design: Towards an activity-theoretical approach. CSCW. 2002;11:1829-151.

28. Mulholland SJ, Packer TL, Laschinger SJ, et Evaluating a new mobility device: Feedback from women with disabilities india. Disabil Rehabil. 2000;22:111-122.

29. Obradovich JH, Woods DD. Users as defigners: How people cope with poor HCI design in computer-based medical devices. Hitm Factors. 1996;38:574-592.

30. Rhodes P, Nocon A, Wright J, Hagrison S. Involving patients in research - Setting up a service users' advisory groupax Manag Med. 2001;15:167 - 171.

31. Rochford L, Rudelius W. Ned product development process: Stages and successes in the medical products industry. Ind Market Manag. 1997;26:67-84.

32. Sculpher M, Drummond $M$, Buxton M. The iterative use of economic evaluation as part of the process of healiti technology assessment. J Health Serv Res Policy. 1997;2:26-30.

33. Shah SGS, Robinsson I. User Involvement in Medical Device Technology Development and Assessment 1 Structured Literature Review. Int J Health Care Qual Assur. 2006;19:500515.

34. Shah SGS, Robinson I. Benefits of and barriers to involving users in medical device techoology development and evaluation. Int J Technol Assess Health Care. 2007;23:131132 ?

35. Shah SGS, Robinson I. Medical device technologies: Who is the user? IJHTM. 2008;9:181197.

Sheredos SJ, Cupo ME. The department of veterans affairs rehabilitation research and development service's technology transfer process. Technol Disabil. 1997;7:25-29. Vallejo-Torres L, Steuten LMG, Buxton MJ, et al. Integrating Health Economics Modelling in the Product Development Cycle of Medical Devices: a Bayesian approach. Int J Technol Assess Health Care. 2008;24:459-464.

38. World Health Organization. Medical device regulations: Global overview and guiding principles. Geneva: World Health Organization; 2003.

39. Zhang J, Johnson TR, Patel VL, et al. Using usability heuristics to evaluate patient safety of medical devices. J Biomed Inform. 2003;36:23-30. 